\title{
Heterophil/Lymphocyte Alterations as a Measure of Stress in American Alligators in Relation to Anthropogenic Disturbance in a Louisiana Intermediate Marsh
}

\author{
Christopher M. Murray ${ }^{1, *}$, Justin L. Rheubert ${ }^{2}$, Michael E. Easter ${ }^{3}$, Mark Merchant ${ }^{4}$ \\ and Brian I. Crother ${ }^{5}$
}

1 Department of Biological Sciences, 331 Funchess Hall, Auburn University, Auburn, AL 36849, USA

2 Department of Biology, The University of Findlay, 300 Davis St. Findlay, OH 45840, USA; E-Mail: rheubert@findlay.edu

3 Everglades Holiday Park, Fort Lauderdale, FL 33332, USA; E-Mail: m.easter05@gmail.com

4 Department of Chemistry, McNeese State University, Lake Charles, LA 70609, USA;

E-Mail: mmerchant@mcneese.edu

5 Department of Biological Sciences, Southeastern Louisiana University, Hammond, LA 70402, USA; E-Mail: bcrother@selu.edu

* Author to whom correspondence should be addressed; E-Mail: cmm004@auburn.edu; Tel.: +1-334-844-8770.

Academic Editor: Merv Fingas

Received: 24 April 2015 / Accepted: 18 May 2015 / Published: 22 May 2015

\begin{abstract}
Numerous anthropogenic factors represent environmental threats to Gulf Coast wetland ecosystems and associated fauna. American alligators (Alligator mississippiensis) have been subject to long-term management and used as ecological and physiological indicators of habitat quality in response to anthropogenic events and stochastic natural disasters. The present study monitored heterophil to lymphocyte ratios (an indicator of stress), in American alligators in a Louisiana intermediate marsh from 2009 to 2011, a time period that coincides with an oil inundation event that occurred in 2011. Sixteen alligators were observed and processed morphometrically (total length, snout-vent length and body mass). Heterophil to lymphocyte ratios were negatively correlated with size, suggesting larger American alligators were physiologically more resilient to the disturbance, more able to actively avoid these poor conditions, or are less affected by localized disturbance.
\end{abstract}


Keywords: alligator; stress; anthropogenic disturbance

\section{Introduction}

Salt Marshes are described as "the most productive of all aquatic environments [1] (p. 22)", and marsh habitat is critical to the Southeastern United States, yet fragile and exposed to disturbance. Anthropogenic impacts, excluding catastrophes, have removed more than $50 \%$ of the historic salt marsh habitat in the United States [2]. Subsurface withdrawal of oil and other resources alone has erased hundreds of square kilometers of tidal marsh in the Gulf of Mexico; marsh habitat is converted to less biologically productive open water or shallow flats [2].

As an apex predator throughout the Southeastern United States, the American alligator is considered a sentinel species [3]. Alligator health and population stability is indicative of the health of the wetlands they inhabit [3]. Alligators have been regarded as, "an excellent model for investigating the effects of chronic exposure to xenobiotic chemicals on reproductive success and embryonic development" [3] (p. 1029). Regionally specific to this study, the seasonal movements, reproductive timing, habitat preference and cultural significance of the species in Louisiana have been extensively studied as a function of Louisiana's management program [4].

Empirically, effects of stressful stochastic events and disturbance have been opportunistically examined. For example, an alligator population subjected to urbanization and recreation was monitored in terms of seasonal activity, abundance, and size-based hierarchical structure [5]. Demographic measurements, such as a 0.19 alligators per hectare density and relative abundance of juveniles provide valuable reference data for future studies. A natural disturbance, the storm surge associated with Hurricane Rita (2005), resulted in significant saltwater inundation in Louisiana coastal marshes. Physiological effects in 11 persisting alligators, as well as over 200 alligators, six months to a year post-inundation, were documented [6]. These included plasma osmolality, sodium, chloride, and potassium plasma levels and indicators of stress (heterophil to lymphocyte $(\mathrm{H}: \mathrm{L})$ ratios $>1: 1$ and corticosterone). This study further validated the reliability of $\mathrm{H}: \mathrm{L}$ ratios as a measure of stress in alligators.

When exposed to adverse conditions, organisms may persist in this environment or, as in the case with mobile taxa, disperse to more favorable habitats. Dispersal is a known response of mobile vertebrates to anthropogenic habitat fragmentation or degradation [7]. In general, crocodilians can be highly mobile, depending on size, and have the ability to disperse freely [8]. In the case of the American alligator, networks of canals, bayous, and bordering rivers potentially provide suitable dispersal corridors for organisms to vacate a contaminated area. Abundance and stress perception of a highly mobile sentinel species are evidence of overall wetland condition over time and the mobility of these animals make them a conservative indicator species [3]. The aims of this study were to monitor variation in American alligator $\mathrm{H}: \mathrm{L}$ ratios (an indicator of stress) in a Louisiana marsh in response to an anthropogenic disturbance, oil inundation from the Deepwater Horizon Oil Spill, by comparing such data to pre-disturbance measurements. We used this information to make inferences regarding local alligator population dynamics. These data are important for developing an understanding of the overall health of specific 
wetlands affected by disturbance and potential management issues associated with American alligators in impacted areas.

\section{Materials and Methods}

All research for this paper was conducted per the guidelines created by Southeastern Louisiana University's IACUC committee (protocol \#: 0016) and all data were collected under an appropriate permit from the Louisiana Department of Wildlife and Fisheries (permit \# LDWF Special Alligator Permit, NA).

Las Conchas Marsh is a $16.2 \mathrm{~km}^{2}$ private intermediate wetland in Southeastern Louisiana and has been used as a study site by the authors for multiple projects, starting in May of 2009 (Figure 1). Baseline $\mathrm{H}: \mathrm{L}$ ratios were collected from this population in September of 2009 for projects other than this one and used as reference data for this study [9]. This marsh was visually confirmed to be inundated with oil (a perceived stressor) from the Deepwater Horizon Oil Spill on 2 July 2010 [10]. The bordering Rigolets (the waterway between Lake Pontchartrain and the Gulf of Mexico) and eastern Lake Pontchartrain were closed to fishing by state authorities on 5 July 2010 as local clean-up efforts were initiated. Clean-up efforts resulted in increased boat travel, human activity in the main public waterways within the marsh, and the presence of increased noise, equipment, and light in the area. Herein, we consider these necessary clean-up efforts as a component of the overall disturbance event and the effects of each component are not separated or specifically analyzed.

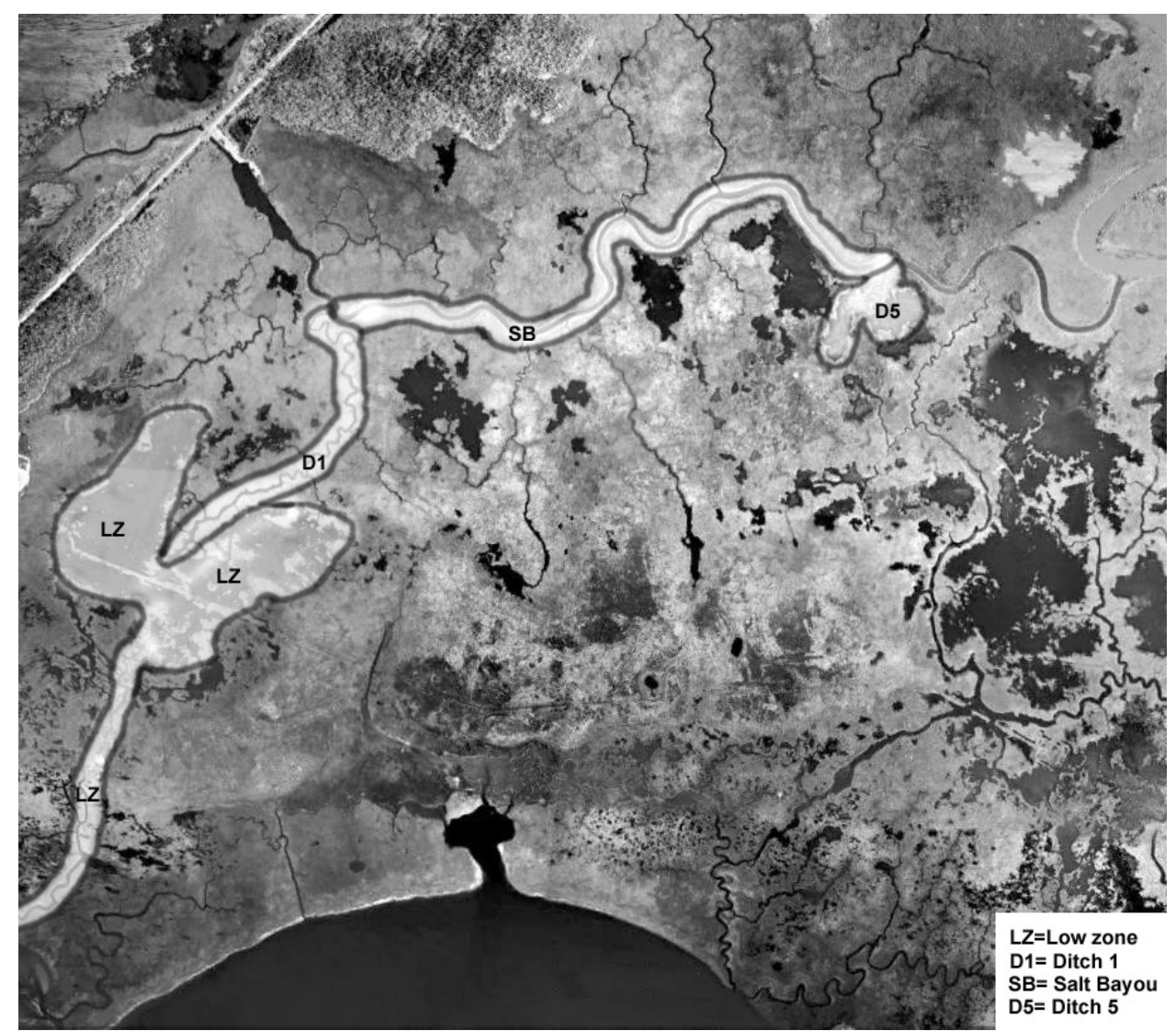

Figure 1. cont. 


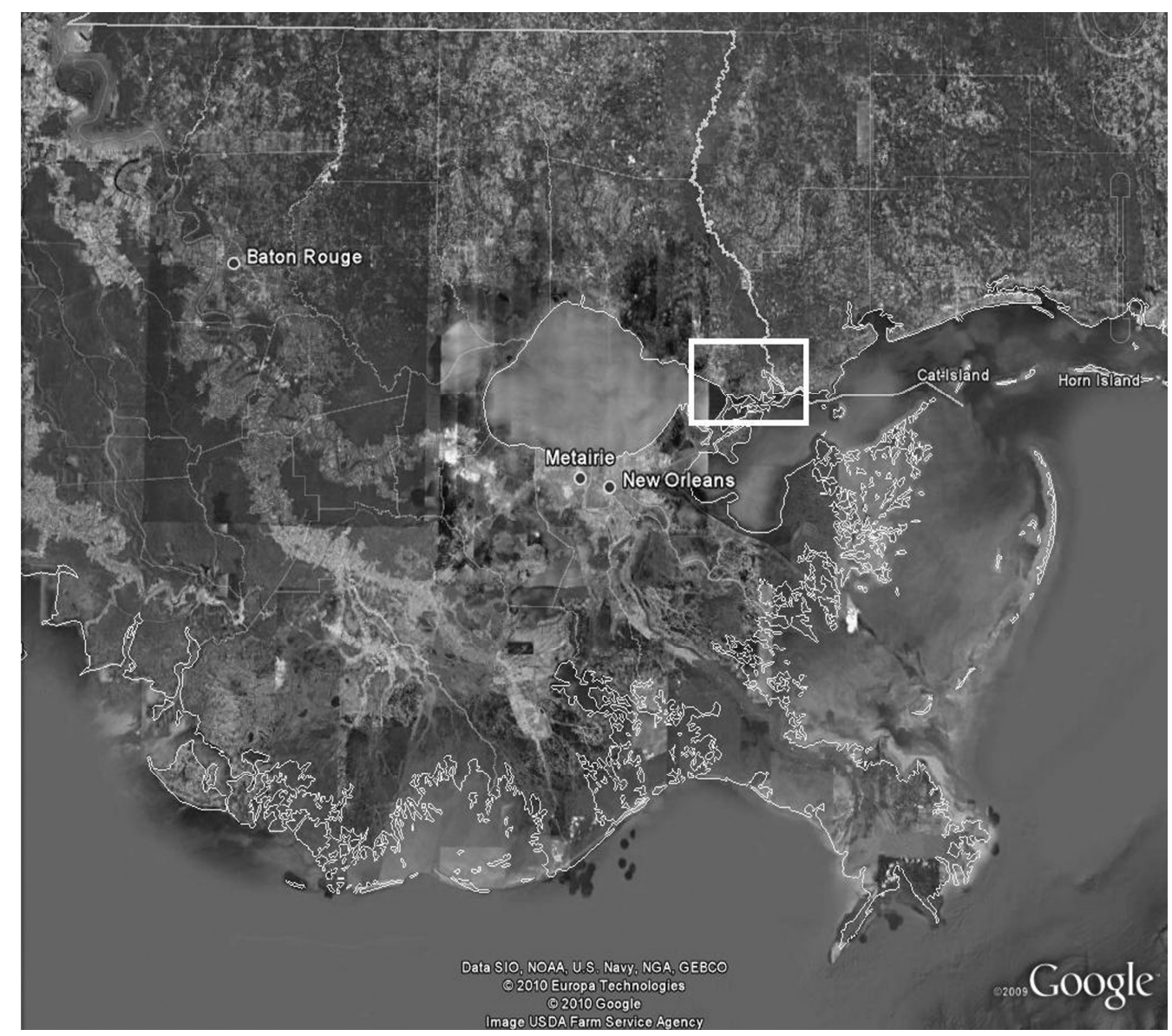

Figure 1. Aerial Image of Las Conchas Marsh (Google Earth 2008) with four sampling sectors highlighted; Low Zone, Ditch 1, Salt Bayou, and Ditch 5. This image accompanied by a southeast Louisiana map showing relative area of study site in highlighted box.

Twelve alligators were captured during the post-inundation sampling period (July-October, 2010) in addition to the four alligators captured in 2009. TL, SVL, and BM were recorded for these individuals. $\mathrm{BM}$ of one animal (SL16) was not recorded as a result of mechanical failures. Animals were captured by snare pole and lifted onto the boat for morphometric data collection in no more than five minutes to avoid handling stress. Following capture, blood samples were obtained to quantify stress response via heterophil to lymphocyte ratios (H:L) as described previously [6,9,11-13]. Briefly, whole blood aliquots were stained with Giemsa-Wright stain and leukocytes were enumerated under light microscopy $(40 \times)$ to obtain H:L ratios for each individual. These ratios were examined to determine relative differences in stress between alligators captured during the pre-and post-oil inundation periods.

A multidimensional scaling (MDS) ordination technique in Primer 6 [14] was used to examine variation in $\mathrm{H}: \mathrm{L}$ ratios between individuals both pre- and post-oil inundation. Clusters were overlaid at a $70 \%$ resemblance level to identify separation in groupings. Least square regression correlations between morphometrics and H:L ratios were examined [15]. A one sample Kolmogorov-Smirnov test with Lilliefor's option was used to determine normality of the data whereas a plot of residuals against predicted values revealed homogeneous variance. A Welch's $t$-test was used to determine difference in $\mathrm{H}: \mathrm{L}$ ratio between pre- and post-inundation samples. 


\section{Results}

Data from four alligators captured pre-disturbance and twelve captured post-disturbance were compared. The average body lengths and mass of four alligators captured pre-oil inundation were: Snout-vent length $(\mathrm{SVL})=109.55 \pm 13.82 \mathrm{~cm}$, total length $(\mathrm{TL})=215.58 \pm 30.05 \mathrm{~cm}$ and body mass $(\mathrm{BM})=39.45 \pm$ $15.51 \mathrm{~kg}$. The twelve alligators captured post-oil inundation had an average SVL, TL, and BM of $79.2 \pm 25.31 \mathrm{~cm}, 165.73 \pm 49.74 \mathrm{~cm}$, and $17.7 \pm 15.99 \mathrm{~kg}$, respectively. A significant negative correlation was recovered between total length and $\mathrm{H}: \mathrm{L}$ ratio in the twelve alligators processed post-disturbance ( $p=0.033, f=6.06$ ) (Figure 2) but no comparable trend was evident among the four alligators observed prior to the oil inundation because sample size, variance in size, and variance in quantified H:L ratios were too low for effective analysis. A similar correlation was recovered between snout-vent length and $\mathrm{H} / \mathrm{L}$ ratio of all captured alligators $(p=0.0505, f=4.94)$ (Figure 2 ).
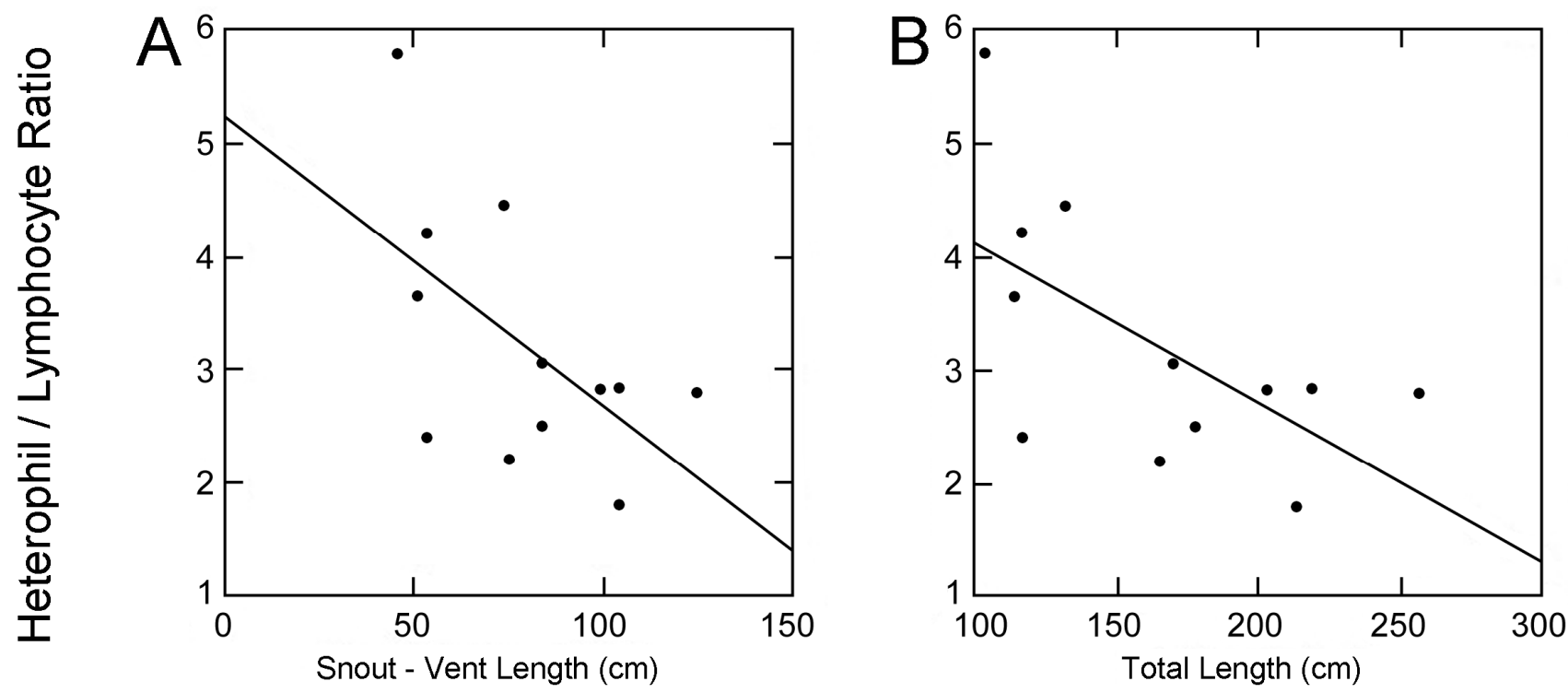

Figure 2. Scatter plots with best-fit lines showing correlations between alligator morphometrics (total length and snout-vent length) and heterophil to lymphocyte ratios post oil inundation (Total length: $p=0.033, f=6.06$, Snout-vent length: $p=0.0505, f=4.94$ ).

Baseline data from pre-oil disturbance revealed $\mathrm{H}$ :L ratios of 1.56, 1.37, 1.25 and 1.24, for the four individuals captured in the 2009 survey [16]. Alligators captured during the post-disturbance period exhibited average $\mathrm{H}: \mathrm{L}$ ratios of 3.20. Post inundation $\mathrm{H}: \mathrm{L}$ ratios were significantly higher than pre inundation $\mathrm{H}: \mathrm{L}$ ratios $(t=5.55, d . f .=12.062, p=0.00012)$. The lowest post-disturbance $\mathrm{H}: \mathrm{L}$ ratio was 1.80 and was recovered from an individual processed seven days after post-disturbance data collection began. All H:L ratios were higher in samples collected post-disturbance compared to respective ratios determined in pre-disturbance samples ( 1) [6] (Table 1). A multidimensional scaling analysis (MDS) revealed separation at $70 \%$ resemblance between three groups (Figure 3 ). 
Table 1. Morphometrics and H:L Ratio data from alligators relative to onset of disturbance.

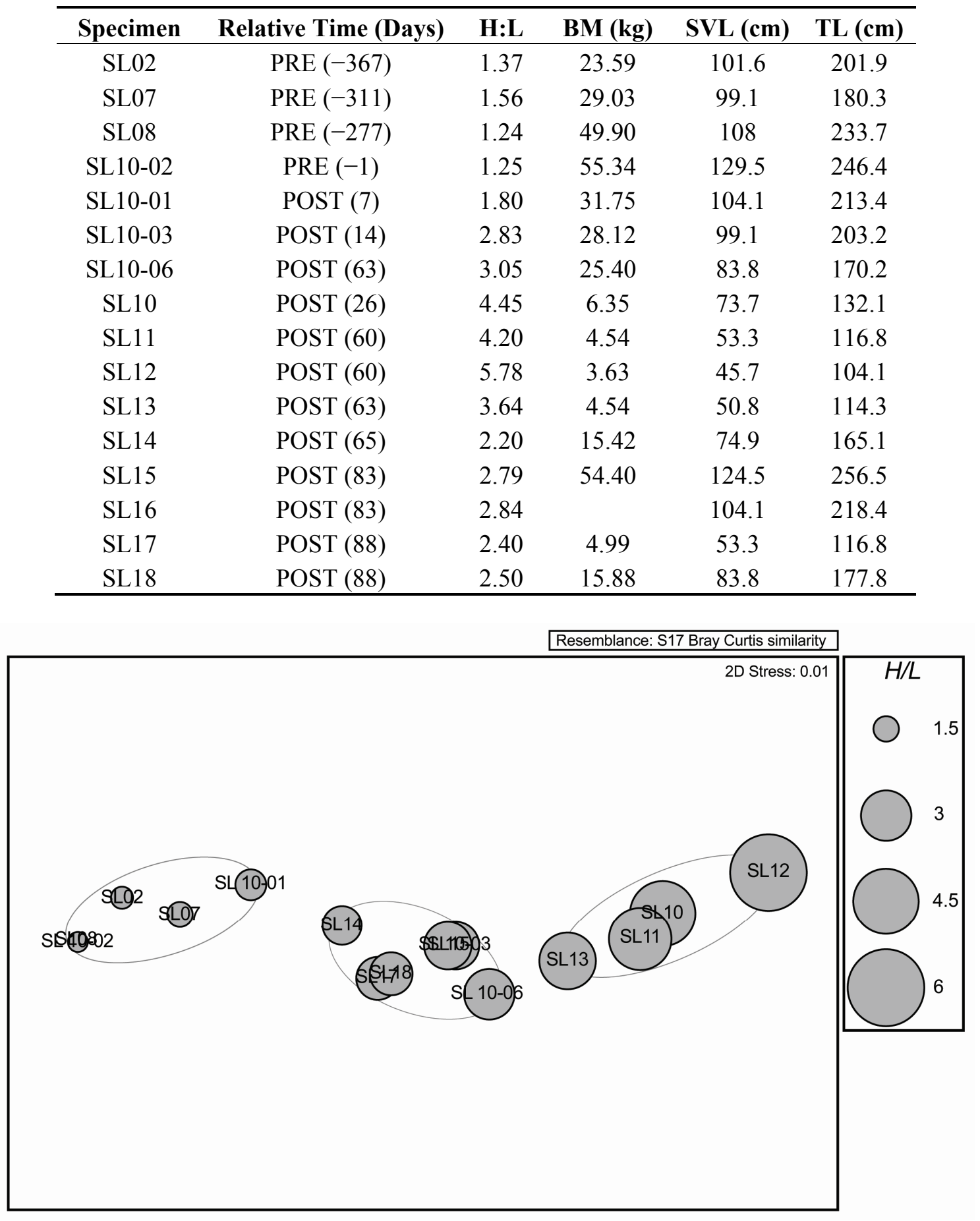

Figure 3. A Multidimensional scaling (MDS) ordination plot based on Bray Curtis similarity of alligator heterophil to lymphocyte ratios post oil inundation with three $70 \%$ resemblance cluster groups highlighted; Pre-disturbance with 1 individual pre- and two post-disturbance groups. Stress (the amount of distortion required to plot a 3D MDS on a 2D plane) $=0.01$.

\section{Discussion}

Alligators captured post-oil inundation in Las Conchas Marsh all exhibited above normal H:L ratios, suggesting these alligators may be stressed. All post-inundation H:L ratios were higher than all 
pre-inundation $\mathrm{H}: \mathrm{L}$ ratios. Multidimensional scaling revealed three clusters (at $70 \%$ resemblance) suggesting three groupings of alligator stress levels. One alligator (SL10-01) captured post-disturbance groups with the H:L ratios of all pre-disturbance alligators (SL02, SL07, SL08, and SL10-02). The remaining two groups exhibited higher H:L ratios with one group exhibiting ratios higher than 3.5 (Figure 3). It is critical to acknowledge that while we recover a temporal correlation between elevated $H: L$ ratios and oil inundation, we do not demonstrate causality. Even though $\mathrm{H}: \mathrm{L}$ ratios are a far better indicator of chronic stress than corticosterone [16], other environmental conditions, immune status [17], small sample size or the size disparity between pre- and post-inundation individuals [18] may have contributed to the elevation of $\mathrm{H}: \mathrm{L}$ ratios in the post-inundation samples. Furthermore, $\mathrm{H}: \mathrm{L}$ ratios $>1$ in the pre-inundation sample suggests that this population may have been already minimally stressed and oil inundation may have exacerbated this response. However, any seasonal effects can likely be dismissed as potential biases because sampling occurred during the same season pre- and post-inundation and because H:L ratios demonstrate a far better indicator of chronic stress, as they do not attenuate as rapidly as corticosterone [16].

Larger alligators were more prevalent during the sampling period prior to disturbance. A negative correlation between alligator total length and H:L ratio (Figure 2) suggests that the stress levels of larger alligators were less affected by the disturbance. Larger alligators are potentially more able to avoid inundated areas and freely disperse into and out of the marsh. It is also possible that the recovered relationship between size and stress exists independently of anthropogenic disturbance but the presence of a stressor was necessary to statistically elucidate the relationship. These hypotheses regarding size-related mobility are contrary to a previous study that reported Crocodylus porosus hatchlings less than six months old dispersing an average of $3.5 \mathrm{~km}$ after human release at their respective nest [19], however, they partially corroborate the finding that sub-adult males are the primary dispersing cohort [20,21]. Although this may be a species specific or system specific behavior, juvenile crocodilians are capable of dispersal to avoid negative conspecific interaction. [19-21].

No dead alligators were found during the sampling periods or otherwise, hinting towards either the active avoidance of these animals to poor environmental conditions [6], or (at least in this case) a non lethal effect of oil on alligators. The West Pearl River, a large waterway that makes up the eastern border of Las Conchas Marsh, provides an evacuation route to additional inland recruitment areas. Further, the size classes of alligators that persisted in the marsh post-oil inundation were hatchlings, juveniles and small adults. This corroborates that dispersal ability is size and/or maturity dependent [8]. Anthropogenic displacement and/or poor environmental conditions during summer months may be particularly critical to the American alligator, because the majority of alligator growth occurs at this time [22]. Low resource availability and stressors may negatively affect annual growth and subsequently affect alligator health and fitness for many years, but this specific disturbance is not considered to be a long-term population stressor based on these data.

\section{Conclusions}

The data set presented in this study show that a size-specific increase in H:L ratios was correlated with the disturbance, and suggests an acute size-specific negative impact on alligator populations. This study utilized a sentinel species and the implications of the findings presented here are likely to apply to other biological or environmental components of this Louisiana intermediate marsh ecosystem. Additional long 
term monitoring of American alligators and other organisms in this region are critical to developing a more thorough understanding of the impacts of anthropogenic events on the flora and fauna of Southeast Louisiana.

\section{Acknowledgments}

We are grateful to Gary Gambel and Dick Kelley for allowing continuous access to the study site and use of equipment, Rob Moreau and Hayden Reno for equipment use, Jonathan Babin, Jennifer Lee and Curtis Hymel for field assistance, and Ruth Elsey for administrative assistance. We also thank David Steen, Kyle Piller, David Sever and David Camak for their proof reading, suggestions, and continuous support.

\section{Author Contributions}

Developed the project idea and design: CMM MEE MM BIC. Performed fieldwork: CMM JLR MEE. Performed analyses: CMM JLR MM. Wrote the paper: CMM BIC.

\section{Conflicts of Interest}

The authors declare no conflict of interest.

\section{References}

1. Gundlach, E.R.; Hayes, M.O. Vulnerability of coastal environments to oil spill impacts. Mar. Technol. Soc. J. 1978, 12, 18-27.

2. Kinnish, M.J. Coastal salt marsh systems in the U.S.: A review of anthropogenic impacts. J. Coast. Res. 2001, 17, 731-748.

3. Milnes, M.R.; Guillette, L.J., Jr. Alligator tales: New lessons about environmental contaminants from a sentinel species. BioScience 2008, 58, 1027-1036.

4. Joanen, T.; McNease, L. Reproductive biology of the American alligator in southwest Louisiana. In Contributions to Herpetology: Reproductive Biology and Disease in Captive Reptiles; SSAR: New York, NY, USA, 1980; Volume 1, pp. 153-159.

5. Lutterschmidt, W.I.; Wasko, D.K. Seasonal activity, relative abundance, and size-class structure of the American alligator (Alligator mississippiensis) in a highly disturbed inland lake. Southwest. Nat. 2006, 51, 346-351.

6. Lance, L.A.; Elsey, R.M.; Butterstein, G.; Trosclair, P.L., III; Merchant, M. The effect of hurricane Rita and subsequent drought on alligators in southwest Louisiana. J. Exp. Zool. 2010, 313, 106-113.

7. Hagan, J.M.; Haegen, V.; Matthew, W.; McKinley, P.S. The early development of forest fragmentation effects on birds. Conserv. Biol. 1996, 10, 88-202.

8. Hutton, J. Movements, home range, dis-persal, and the separation of size classes in Nile Crocodiles. Am. Zool. 1989, 29, 1033-1049.

9. Murray, C.M.; Easter, M.; Merchant, M.; Cooper, A.; Crother, B.I. Can reproductive allometry assess population marginality in crocodilians? A comparative analysis of Gulf Coast American Alligator (Alligator mississippiensis) populations. Copeia 2013, 2013, 268-276.

10. Report on Oil Sightings Throughout Coastal Louisiana. Available online: http://www.emergency.louisiana.gov/ (accessed on 6 July 2010). 
11. Gross, W.B.; Siegel, H.S. Evaluation of the heterophil/lymphocyte ratio as a measure of stress in chickens. Avian. Dis. 1983, 27, 972-979.

12. Davis, A.K.; Maney D.L.; Maerz, J.C. The use of leukocyte profiles to measure stress in vertebrates: A review for ecologists. Funct. Ecol. 2008, 22, 760-772.

13. Zippel, K.C.; Lilywhite, H.B.; Mladnich, C.R.J. Anatomy of the crocodilian spinal vein. J. Morphol. 2003, 258, 327-335.

14. Clarke, K.R.; Gorley. R.N. PRIMER v6; PRIMER-E Ltd.: Plymouth, UK, 2011.

15. Systat Software. Systat 10.2; Systat Software, Inc.: Richmond, CA, USA, 2002.

16. Goessling, J.M.; Kennedy, H.; Mendonça, M.T.; Wilson, A.E. A meta-analysis of plasma corticosterone and heterophil: Lymphocyte ratios-is there conservation of physiological stress responses over time? Funct. Ecol. 2015, doi:10.1111/1365-2435.12442.

17. Glassman, A.B.; Bennett, C.E.; Hazen, T.C. Peripheral blood components in Alligator mississippiensis. Trans. Am. Microsc. Soc. 1981, 100, 210-215.

18. Wilcoxen, T.E.; Boughton, R.K.; Bridge, E.S.; Rensel, M.A.; Schoech, S.J. Age related differences in baseline and stress induced corticosterone in Florida scrub jays. Gen. Comp. Endocrinol. 2011, 173, 461-466.

19. Magnusson, W.E. Dispersal of hatchling crocodiles (Crocodylus porosus) (Reptilia, Crocodilidae). J. Herpetol. 1979, 13, 227-231.

20. Platt, S.G.; Thorbjarnarson, J.B. Status and conservation of thr American crocodile, Crocodylus acutus, in Belize. Biol. Conserv. 2000, 96, 13-20.

21. Murray, C.M.; Easter, M.E.; Padilla, S.; Garrigos, D.B.; Stone, J.A.; Bolanos-Montero, J.; Sasa, M.; Guyer, C. Cohort-dependent sex ratio biases in thr American crocodiles (Crocodylus acutus) of the Tempisque Basin. In Copeia; American Society of Ichthyologists and Herpetologists: Lawrence, KS, USA, 2015.

22. Chabreck, R.H.; Joanen, T. Growth rates of American alligators in Louisiana. Herpetologica 1979, $13,51-57$.

(C) 2015 by the authors; licensee MDPI, Basel, Switzerland. This article is an open access article distributed under the terms and conditions of the Creative Commons Attribution license (http://creativecommons.org/licenses/by/4.0/). 